\title{
Scientific Analysis of Mantra-Based Meditation and Its Beneficial Effects: An Overview
}

\author{
Jai Paul Dudeja \\ Professor and Director, Amity University Haryana, Gurgaon 122413, India. \\ drjpdudeja@gmail.com, Mobile: $91-9312247845$
}

\begin{abstract}
The word 'Meditation' comes from the Latin root "meditatum", which means "to ponder". Meditation is a technique for resting the mind leading to peace, happiness, bliss, and self-realization. There are a large number of meditation techniques in the world. Mantra-based meditation is one such technique in which a sound, word or phrase (called 'mantra') is recited either aloud or silently during meditation. It has been established by the experience as well as the experiments that the correct frequency of mantra sound, along with the correct intent, helps the practioner oxygenate the brain, reduce heart rate, blood pressure, get cured by many ailments, create calm brainwave activity and achieve immunity from outside mental disturbances. The theoretical and the experimental aspects of mantra-based meditation technique are analyzed scientifically in this paper. The primary aim of this paper is to make the larger number of people, including the intelligentsia, aware of this wonderful gift of Almighty so that they themselves could try practicing meditation for their own benefit and consequently transmit peaceful vibrations to the society in this age of planetary turmoil.
\end{abstract}

Keywords: meditation, mantra, sound, healing, wellness, bliss, calmness.

\section{INTRODUCTION}

We are in such an extraordinary time of planetary turmoil, that it is mandatory for us to find a solution to this situation and hence have a tool that can help us reach our next level of quantum evolution. The goal of using this tool is to experience a state beyond the mind's levels of thinking, feeling, and analyzing. To achieve this, we must create a state within ourselves that is still and one-pointed so that the mind becomes silent. This tool is called the 'meditation'. The word 'Meditation' comes from the Latin root "meditatum", which means "to ponder".

\section{$1.1 \quad$ What is Meditation?}

Meditation is a technique for resting the mind and attaining a state of consciousness that is totally different from the normal waking state, a sleeping state or a dreaming state. It is a transcendental state of consciousness. During and after the meditation the mind reaches a state of restful alertness. Meditation is a practice of focus or relaxed attention or contemplation upon a thought or a sound or an object or on visualization or on the breath, in order to increase awareness of the self at the present moment, reduce stress, promote relaxation, and enhance personal and spiritual growth. The regular practitioner of meditation performs the journey towards peace, happiness, bliss, and self-realization.

\subsection{Types of Meditation Techniques}

There are a large number of meditation techniques in the world. We can classify meditation techniques into three broad categories: (i) focused attention (ii) open monitoring, and (ii) effortless process.

Out of this large number, relatively more known techniques of meditation are listed below [1]:

1.2.1 Hindu Meditation (Vedic \& Yogic): (i) Mantra Meditation (the topic of this paper) (ii) Transcendental meditation, (iii) Third Eye meditation, (iv) Chakra meditation, (v) Gazing meditation (Trataka), (vi) Kriya
Yoga, (vii) Sound meditation (Nada Yoga), (viii) Tantra, (ix) Pranayama, (x) Sahaj Yoga, (xi) Raj Yoga, (xii) Kundalini meditation, (xiii) Self enquiry and "I Am" meditation.

1.2.2 Buddhist Meditation : (i) Zen meditation (Zazen), (ii) Vipassana meditation, (iii) Mindful meditation, (iv) Metta meditation (Love \& Kindness).

1.2.3 Jain Meditation : (i) Preksha meditation, (ii) Leshya meditation, (iii) Kayotsarga Meditation, (iv) Pindastha meditation, (v) Padastha meditation, (vi) Rupastha meditation, (vii) Rupatita meditation, (viii) Savirya meditation.

1.2.4 Meditation in Sikhism: Nam Japa or Nam Simran.

1.2.5 Parsi Meditation in Zoroastrianism: (i) Meditation as mentioned in Gathas, (ii) Meditation on Fire, (iii) Prayer meditation.

1.2.6 Christian Meditation

1.2.7 Chinese Meditation: (i) Taoist (Emptiness) meditation, (ii) Taoist (Breathing) meditation, (iii) Taoist (Neiguan) meditation, (iv) Qigong (Chi kung).

1.2.8 Guided Meditation: (i) Traditional meditation, (ii) Guided imagery, (iii) Relaxation and body scans, (iv) Affirmation, and (v) Binaural beats.

\subsection{What is Mantra?}

The word mantra comes from the ancient Sanskrit language. 'Man' means mind, and 'tra' means release. So a mantra is a combination of transcendental sounds meant to release the mind from all the anxieties of material life. One gets miraculous advantages by making use of the causal energy of Mantra. In the ancient Hindu scriptures called Vedas, it is mentioned that "In the beginning was Brahm, with whom was the vibration (of sound) and the vibration was Brahm." The mantra plays the role of getting transformed into potential energy. The "mantra", could be the Divine name, one may call this "Om" or "Brahm Nad" or any other word in other religions and faiths. [2] The mantra could even be a meaningless sound, 
the frequency of which helps transforms the user to a new level of consciousness.

\subsection{What is Mantra-Based Meditation?}

Mantra meditation is the process of quieting and focusing the mind using a sound, word or phrase (called 'mantra') recited either aloud or silently. The purpose of mantra meditation is for spiritual growth, or for relaxation of mind. It is also known as 'japa' meditation, from the Sanskrit word for "muttering." The mantra meditator achieves a state of 'restful alertness' after performing this process. Everything is in a state of vibration and when we are in a natural, resonant vibration, we are in a state of good health. But if some part of the body begins to vibrate at a wrong frequency, the energy becomes stuck and disease sets in. Therefore, through 'mantric' chanting, one can cause the stuck energy to become released, and we can return to our natural state of resonance, thus affecting a cure [3]. It has been found that the sounds of specific mantras chanting will cause the left and right hemispheres of the brain to synchronize. Such chanting will also help oxygenate the brain, reduce our heart rate, blood pressure and assist in creating calm brainwave activity. There is a reason why most of the prayer/meditation on the planet is vocalized [4]. Sound amplifies our prayers. Through positive intentionalized and internalized sound, we can generate the miraculous effects. Every sound that we make is actually a composite of sounds - a fundamental frequency and geometric multiples of that sound, called harmonics or overtones. These harmonics are whole number ratios, 1:1, 2:1, 3:2, etc. These vocal harmonics make up the "timbre" or tone color of sound and are responsible for the way our individual voices sound. It is a field of all possibilities. We can make new neural synaptic connections in the brain with vocal harmonics. Harmonics can also improve our vocal quality, hearing, change our brain pattern and even heighten our consciousness [4].

\section{II.TYPES OF MANTRAS (SOUNDS) USED IN MANTRA MEDITATION}

As mentioned earlier, hundreds and thousands of meaningful as well as meaningless sounds are used by different people in the mantra meditation. Whereas some of these sounds could be universal or common to all (like 'Om' in Hindu philosophy) and while some sounds may be suiting to specific individuals. Some of the initiators of meditation require the 'initiated person' to keep this mantra secret and not reveal to anybody.

\subsection{The 'Om' Mantra}

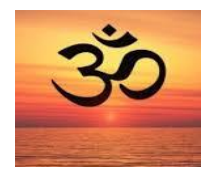

Everything in the universe is pulsating and vibrating nothing is really standing still ! "Om" is said to be the original, primordial tone of the universe-the original sound of creation, if you like. It is interesting to note that the astrophysicists have now detected echoes of the "Big
Bang" that happened at the beginning of time. And this sound they have detected is a humming sound, very much like that of the "Om".

The sound 'Om', when chanted, vibrates at the frequency of $136.1 \mathrm{~Hz}$, which is the same vibrational frequency found throughout everything in nature [5-7]. Interestingly, it is also the frequency of the $32^{\text {nd }}$ Octave of the Earth Year.

\section{Illustration:}

Time Period $(\mathrm{T})$ of one rotation of earth round the sun $=$ 365.256 days $\times 24 \mathrm{hrs} /$ day $\times 60 \mathrm{~min} / \mathrm{hr} \times 60 \mathrm{sec} / \mathrm{min}=$ $31558118.4 \mathrm{sec}$

So, the frequency $(\mathrm{f})$ of earth year $=1 / \mathrm{T}=3.168757 \times 10^{-8}$ $\mathrm{Hz}$.

If we multiply this with $32^{\text {nd }}$ octave, that is. with $4294967296\left(=2^{32}\right)$,

we get $=136.1 \mathrm{~Hz}=$ frequency of the sound ' $\mathrm{OM}$ '.

If one makes the sound of OM in front of a drop of liquid, it will transform itself into a Sri Yantra which is very specific visual form which is symmetrical and also holographic [8]. This Sri Yantra was revealed to Maharishis with 12 strand DNA and king sized pineal glands more than 8000 BC. Sanskrit Mantras have precise golden ratio of 1.618 sound harmonics ( Fibonacci/ Sri Yantra ) in digital mathematical and geometrical precision and Sri Yantra is based on that ratio. The cymatics of OM is the Sri Yantra whose angle was used to construct the Egyptian Pyramids.

\subsection{The Gayatri Mantra}



It is the most significant and the most effective mantra (hymn), according to ancient Hindu scriptures. Its meaning, in brief is: "We meditate on that most adored Supreme Lord, the creator, whose effulgence (divine light) illumines all realms (physical, mental and spiritual). May this divine light illumine our intellect."

It is interesting to note that Dr. Howard Steingull, an American Scientist has established [9] that recitation of Gayatri Mantra produces a frequency of $110,000 \mathrm{~Hz}(>20$ $\mathrm{kHz}$ ?). The patterns of chanting of Mantras are so designed that they latently contain the essence of the music, life sustaining energies emanating from the cosmic energy centre of the corresponding Mantras. (The cosmic energy centre a deity associated with the Gayatri Mantra is Sun). Uttering of Gayatri Mantra produces vibrations which are soothing to human mind, all plant and animal life.

2.3 Anuswaram (Nasal Sound), MMMM and

Production of Nitric Oxide in the Body: 
The anuswaram (nasal sound) MMMM humming boosts the production of Nitric oxide in the body. This was known to Indians and documented more than 7000 years ago [8]. Nadaswaram (Shehnai) is an ancient musical instrument which produces similar nasal sound. Many mantras which end with Anuswaram MMMM, produce Nitric oxide, which is a molecule that our body produces to help its 50 trillion cells communicate with each other by transmitting signals throughout the entire body. Nitric Oxide (NO) is an important regulator and mediator of numerous processes in the nervous, immune, and cardiovascular systems. These include vascular smooth muscle relaxation, resulting in arterial vasodilation and increasing blood flow. People with diabetes usually have lower levels of Nitric oxide than those without diabetes. Stems and Flowers cut from their original plants can survive for longer time if supplied with Nitric Oxide. Opiate drug Morphine, the addictive pain killer, works by an increase in Nitric Oxide release. Nitroglycerin and Amyl Nitrite tablets serve as vasodilators because they are converted to Nitric Oxide in the body, to ease angina pain (heart pain). Sufficient amounts of Nitric Oxide in blood controls Blood Pressure. When the human body reaches the age of 27 years, the secretion of nitric oxide is at its peak. As one gets older, the production of nitric oxide in the human body declines gradually.

\subsection{Kundalini, Seven Chakras and Beej Mantras}

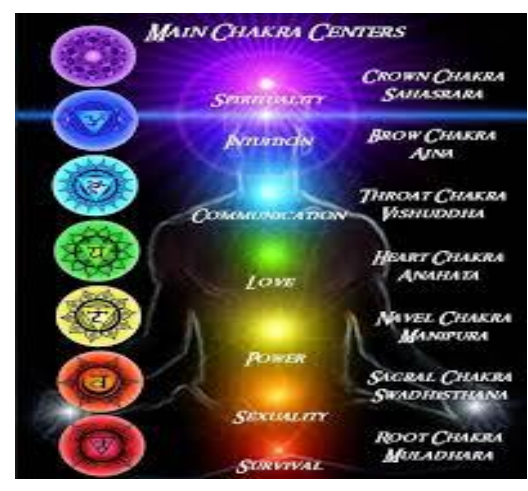

Kundalini is a Sanskrit word, which means "coiled one". It refers to a form of primal energy (or shakti) said to be located at the base of the spine. Different spiritual traditions teach methods of "awakening" kundalini for the purpose of reaching spiritual enlightenment and a range of supernormal powers.

Chakras can be simulated to the spinning discs that feed energy into specific parts of the physical body. Chakras are the energetic wheels of light that transduce subtle energy into the body. A Beej Mantra is the shortest form of a Mantra just like a beej (seed) which when sown grows into a tree. The healing due to Beej Mantras occurs due to the balancing and alignment of the chakras. It is good to be able to direct one's attention and intention when one is attempting to resonate with a particular chakra with the particular sound or Beej Mantra.

There are seven chakras in our body, each located at a specific point in the body, shown in the figure. There is a Beej

Mantra specific to each chakra [10], which is described in the following table (Table 1):

Table 1

\begin{tabular}{|c|c|c|c|c|c|c|c|}
\hline Chakra No. & & & & & & & \\
\hline & 1 & 2 & 3 & 4 & 5 & 6 & 7 \\
\hline Chakra Type & $\begin{array}{l}\text { Muladhara } \\
\text { (मूलाधार) }\end{array}$ & $\begin{array}{l}\text { Swadhisthana } \\
\text { (स्वाधिष्ठान) }\end{array}$ & Manipura (मणिपूर) & $\begin{array}{l}\text { Anahata } \\
\text { (अनाहत) }\end{array}$ & Vishuddha (विशुद्ध) & $\begin{array}{c}\text { Ajna (आज्ञा) } \\
\text { Brow }\end{array}$ & $\begin{array}{l}\text { Sahasrara } \\
\text { (सहस्रार) }\end{array}$ \\
\hline Symbol & & & & & & & \\
\hline Chakra Location & $\begin{array}{l}\text { Cervix/ } \\
\text { Perineum }\end{array}$ & $\begin{array}{l}\text { Last bone in spinal } \\
\text { cord }\end{array}$ & Navel area & Heart area & Throat \& neck area & $\begin{array}{c}\text { Pineal gland or } \\
\text { third eye }\end{array}$ & $\begin{array}{l}\text { Top of the } \\
\text { head; 'Soft } \\
\text { spot' of a } \\
\text { newborn }\end{array}$ \\
\hline Name of Chakra & $\begin{array}{c}\text { Base or Root } \\
\text { Chakra }\end{array}$ & Sacral Chakra & Solar Plexus Chakra & Heart Chakra & Throat Chakra & $\begin{array}{c}\text { Third Eye } \\
\text { Chakra }\end{array}$ & Crown Chakra \\
\hline Element & Earth & Water & Fire & Wind & Sky & Body & No Element \\
\hline Specific Mantra & Lam & Vam & Ram & Yam & Ham & $\mathrm{Om}$ & No Sound \\
\hline $\begin{array}{l}\text { Frequency of } \\
\text { Mantra }(\mathrm{Hz})\end{array}$ & $\begin{array}{c}261.6,523.3 \\
1046.5,2093 \\
4186\end{array}$ & $\begin{array}{c}293.7,587.3,1174.7 \\
2349.3,4698.7\end{array}$ & $\begin{array}{c}329.6,659.3,1318.5 \\
2637.1,5274.1\end{array}$ & $\begin{array}{c}349.2,698.5, \\
1396.9,2793.9, \\
5587.7\end{array}$ & $\begin{array}{c}196,392,784,1568, \\
3136\end{array}$ & $\begin{array}{c}110,220,440, \\
880,1760, \\
3520.136 .1\end{array}$ & $\begin{array}{c}123.5,246.9, \\
493.9,987.8, \\
1975.5,3951.1\end{array}$ \\
\hline $\begin{array}{l}\text { Role of Healthy } \\
\text { Chakra }\end{array}$ & $\begin{array}{l}\text { Keeps you } \\
\text { Grounded. } \\
\text { Connects your feet } \\
\text { to the Earth. }\end{array}$ & $\begin{array}{c}\text { Emotions, Passion, } \\
\text { intuition and } \\
\text { creativity. }\end{array}$ & $\begin{array}{c}\text { Confidence, } \\
\text { Assertiveness, Will } \\
\text { Power. }\end{array}$ & $\begin{array}{l}\text { Love, Kindness, } \\
\text { Compassion, } \\
\text { Harmonious } \\
\text { relationships }\end{array}$ & $\begin{array}{l}\text { Self-Expression and } \\
\text { Open } \\
\text { communication. }\end{array}$ & $\begin{array}{l}\text { Insight and } \\
\text { visualization. } \\
\text { Opens up } \\
\text { perceptive } \\
\text { ability. }\end{array}$ & $\begin{array}{c}\text { Wisdom. } \\
\text { Connecting you } \\
\text { to your higher } \\
\text { Self and } \\
\text { spirituality, } \\
\text { timelessness, } \\
\text { language of } \\
\text { light } \\
\end{array}$ \\
\hline
\end{tabular}




\section{III.LEVELS OF SOUND OF MANTRAS}

The Vedas recognize four stages of the manifestation of sound [11].

(i) The grossest form of sound, Vaikhari is normal audible sound, including speech.

(ii) More subtle is Madhyama, a whispered sound with no audible effect.

(iii) As you move within, you experience Pashyanti. These are mental sounds such as songs in the head or a dream. It is also the visualization of sound such as silently listening to your thoughts or the silent repetition of a mantra.

(iv) Finally you reach Para or transcendental sound. This is pre-manifest sound in its subtlest state as light or pure silence. This is the root or potential of all sounds, sometimes referred to as the "unstuck sound."

The important thing which is being emphasized by the author here is that as we go from various levels of sound from vaikhari to para, not only the intensity of sound changes, simultaneously its frequency can also change thereby synchronizing with the sympathetic nervous system of the meditator. This observation of the author requires to be validated experimentally.
The basic aim of any form of meditation, including the mantra-based meditation, is to induce certain sympathetic frequencies in the oscillation of neurotransmitters, coherently and synergistically, in order to achieve the desirable effects: like achieving calmness, controlled blood pressure, clarity of thoughts, immunity from outside disturbance, achieving restful alertness, happiness, peace, bliss and enlightenment.

So the Brain waves are produced by the synchronized electrical pulses from a large number of neurotransmitters communicating with each other simultaneously.

Broadly speaking, there are the following five types of brain waves to be mentioned in the present context:

(i) Gamma waves: for inspiration, higher learning and focus. Their frequencies are $>40 \mathrm{~Hz}$.

(ii) Beta waves: for alertness, concentration, and cognition. Their frequencies are in the range of $13-40$ $\mathrm{Hz}$.

(iii) Alpha waves: for visualization, relaxation, and creativity. Their frequencies are in the range of $7-13 \mathrm{~Hz}$. (iv) Theta waves: for meditation, intuition, and memory. Their frequencies are in the range of $4-7 \mathrm{~Hz}$, and finally, (v) Delta waves: detached awareness, healing and sleep. Their frequencies are $<4 \mathrm{~Hz}$.

The following pattern of waveforms is illustrative of some of these waves:

\section{IV.BRAINWAVES}

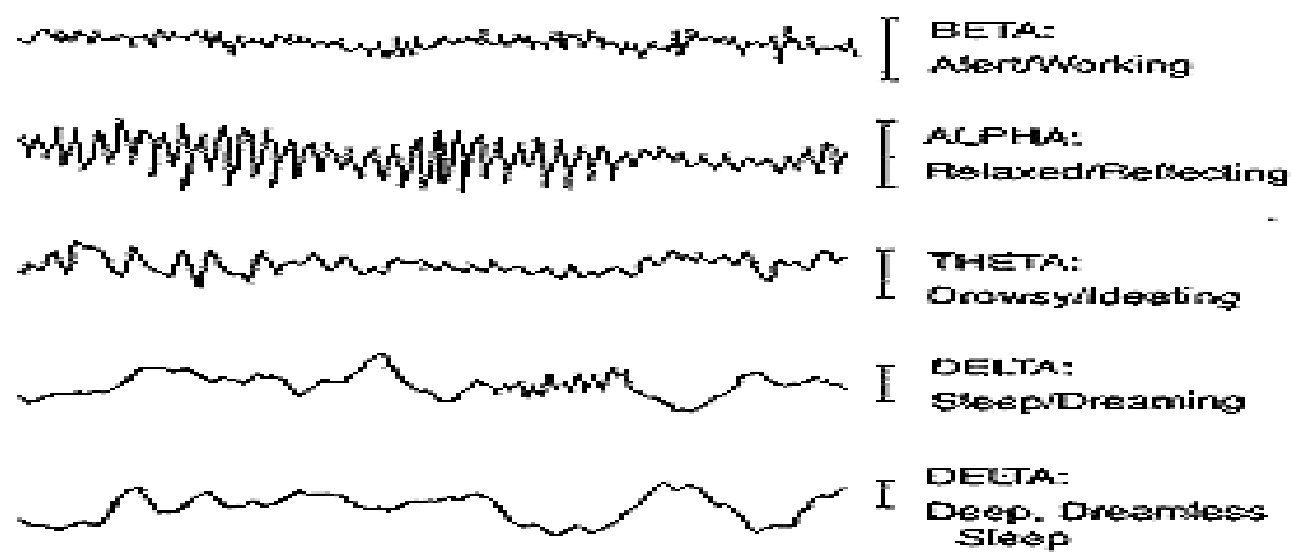

\subsection{Gamma Waves (40-100 Hz):}

Gamma Brain Waves are the fastest brainwaves (high frequency) and the most recently discovered brain wave state, relate to simultaneous processing of information from different brain areas. These are involved in higher processing tasks as well as cognitive functioning. This is important for learning, memory and information processing. Too much Gamma Waves result to: Anxiety, High Arousal, Stress. Too little Gamma Waves result to: ADHD (Attention-Deficit/HyperactivityDisorder), Depression, Learning Disabilities. Optimal Gamma

Waves result to: Binding Senses, cognition, information processing, learning, perception, REM (Rapid Eye Movement) sleep.

\subsection{Beta Waves (12-40 Hz):}

Beta Brain Waves are associated with normal waking consciousness and a heightened state of alertness, logic and critical reasoning. Having the right amount of beta allows us to focus to our task whether in class room, work place or sports ground. However, exposing too much beta waves also results to too much stress. Too much Beta Waves result to: Anxiety, High Arousal, Inability to Relax and Stress. Too little Beta Waves result to: ADHD (Attention-Deficit/Hyperactivity Disorder), day-dreaming, depression, poor cognition, optimal Beta Waves result to: Conscious focus, memory, and problem solving.

4.3 Alpha Waves $(8-12 \mathrm{~Hz})$ :

Alpha Brain Waves are dominant during quietly flowing thoughts while one is in deep relaxation, or when one is slipping into a lovely daydream or during light meditation. Alpha is the frequency between our conscious thinking 
and subconscious mind: This is Light Meditation State. Too much Alpha Waves result to: Daydreaming, inability to focus, too relaxed. Too little Alpha Waves result to: Anxiety, High Stress, Insomnia, and OCD (Obsessive Compulsive Disorder). Optimal Alpha Waves result to: Relaxation, and Natural Flow State of thoughts.

\subsection{Theta Waves $(4-8 \mathrm{~Hz})$ :}

Theta Brain Waves occur most often in sleep but are also dominant during deep meditation. In theta we are in a dream; vivid imagery, intuition and information beyond normal consciousness awareness. It helps us improve our intuition, creativity, and makes us feel more natural. Too much Theta Waves result to: ADHD, depression, hyperactivity, impulsivity, and inattentiveness.

Too little Theta Waves result to: Anxiety, poor emotional awareness, and stress. Optimal Theta Waves result to: Flow State, Creativity, emotional connection, intuition, and relaxation

4.5 Delta Waves (0-4 Hz):

Delta Brain Waves are the slowest but loudest brainwaves (low frequency). These are experienced in a deep, dreamless sleep and in very deep, transcendental meditation. These are also found most often in infants as well as young children. Deep sleep is important for the healing process - as it is linked with deep healing and regeneration. Too much Delta Waves result to: Brain injuries, learning problems, inability to think, and severe ADHD. Too little Delta Waves result to: Inability to rejuvenate body, inability to revitalize the brain, and poor sleep. Optimal Delta Waves result to: Immune System, natural healing, restorative sleep / deep sleep.

\section{V.RESULTS OF SOME EXPERIMENTS}

5.1 Jean Paul Banquet, conducted some experiments on the subjects practicing Mantra-based Transcendental Meditation (TM) and observed the following results [16]:

(i) Frequency Change: Mantra meditation leads to shift from alpha to slow frequencies, mostly theta and mixed frequencies, sometimes low- and medium-voltage delta frequencies. high-voltage beta, at approximately $20 \mathrm{~Hz}$, appears, usually mixed with alpha and theta, with simultaneous disappearance of higher beta frequencies. The dominant alpha usually slows down by one or two $\mathrm{Hz}$.

(ii) Form and Amplitude: The amplitude of alpha is increased at the end of meditation.

(iii) Variation in Time: Continuous alteration of alpha and mixed frequencies is typical. Alpha periods predominate at the beginning of meditation. Low mixed theta and beta, different from drowsiness, are prominent in deep meditation. Rhythmic higher voltage alpha frequencies return at the end.

5.2 Experiments were conducted by Dr. Robert Keith Wallace in the School of Medicine of the University of California to study the physiological effects of Transcendental Meditation [17]. It was found that during meditation, oxygen consumption, carbon dioxide elimination, cardiac output, heart rate, and respiration rate slowly decreased. Skin resistance significantly increased, and the EEG showed specific changes in certain frequencies. Base excess significantly decreased during meditation. Arterial blood pressure, $\mathrm{pH}$ decreased slightly and arterial lactate deceased markedly during meditation and remained low after meditation. These results distinguished the state of consciousness produced by the meditation from the commonly encountered states of consciousness such as waking, dreaming and sleeping and the altered states such as hypnosis and conditioning. So it was proved that the meditation produces a fourth major state of consciousness that may have practical clinical applications.

5.3 Meditation therapy has been used by some doctors in Bombay Hospital [18] in preventing various diseases particularly cardiovascular ailments. Meditation was shown to be effective in coronary artery disease and various risk factors involved - particularly hypertension, hypercholesterolaemia and diabetes. Numbers of studies have shown that regular practice of Mantra Meditation has been useful in reducing blood pressure significantly and lowering cholesterol and blood sugar.

5.4 In a paper presented in a conference in 1989 [19], Dr. Selvamurthy et al reported to have observed neurophysioligical effects of the Mantras of a special kind. In this experimental study, 8 healthy men were chosen as subjects. They reported at 4:00 PM on two consecutive days. First day, instead of the prescribed Mantras, some irrelevant syllables were uttered to them. Next day, the proper Mantras were uttered and recording of physiological parameters viz. Heart rate, ECG, EEG, GSR (Galvanic Skin Response), blood pressure etc. were made on both days. The results showed that while the mind (brain waves) remained unaltered on the first day, significant improvement occurred on the second day.

\section{IMPORTANCE OF PRONUNCIATION OF MANTRAS AND FAITH}

Sound (nad) is the basic component of creation and is based on the sciences of Music and Mantra. Now pronounce 'Om' as one usually does and note the spiritual experience. Then prolong the duration of Om three to four times, that is 'O....m....', and then record the experience. With the prolonged Om one experiences more energy or goes into a kind of trance, than with the usual Om. The reason for this is that with the usual pronunciation only one direction is stimulated whereas with the prolonged variation all the eight directions are stimulated. It is for this very reason that usually when a note is prolonged a positive effect is obtained.

Another important aspect of mantras is their correct pronunciation. It is mentioned in Hindus' ancient scriptures that: 


\section{मन्त्रो हीन: स्वरोत वर्णो या मिथ्याप्युटो न तमर्थमाह स वार्वज्रो यजमानां हिनस्ति यथेन्द्रशत्रु: स्वरोपेराधात}

The meaning: The mantra without proper pronunciation of vowels (svar) and consonants (varna) that is the utterance of a mantra in a faulty manner makes it faulty and does not convey the intended meaning. Instead it gets converted into a verbal thunderbolt and may harms the one chanting it.

Lastly and the most important aspect is the 'Faith' with which are pronounced. Science may not have the answer to this aspect as of now but it has been established by the practioners of mantra-based meditation that "correct pronunciation of mantras (sound) plus the faith or intent with which these mantras are uttered, brings the desired beneficial effects to the meditators.

\section{CONCLUSION}

Almost all the religions, sects and faiths on this planet wish their followers and other human beings to achieve a peaceful mind, with coherent thoughts leading to a healthy body, mind and soul, through the practice of some technique or meditation. Hence there are a very large number of meditation techniques in the world leading to the same goal. Mantra-based meditation is one such technique. This technique can be practiced by anyone in the world without any conflict of faith with the respective religion . Besides the correct frequency of the sound of mantra suiting to a specific individual, the addition of faith can bring miraculous effects to the practioner of this meditation technique. In this paper, through a scientific analysis, it has been established that how a practioner of mantra meditation can achieve a disease-free body, a calm mind, clear and coherent thinking, enhancement of intelligence quotient, and successfully perform the journey towards attaining bliss, self-realization and enlightenment. The primary aim of this paper is to make the larger number of people, including the intelligentsia, aware of this wonderful gift of Almighty so that they themselves could try practicing meditation for their own benefit and consequently transmit peaceful vibrations to the society in this age of planetary turmoil.

\section{REFERENCES}

[1] Dienstmann, Giovanni; "Types of Meditation...", in Live and Dare, 2015.

[2] Goldman, Jonathan; "The Divine Name: Invoke the Sacred Sound That Can Heal and Transform”, Hay House, 2015.

[3] Goldman, Jonathan; "Shifting Frequencies". Light Technology Publications, 1998.

[4] Goldman, Jonathan; "Healing Sound: The Power of Harmonics", Inner Traditions, 2002.

[5] Heisnam Jina Devi, NVC Swamy and H.R. Nagendra, "Spectral analysis of the Vedic mantra Omkara", Ind. J. of Traditional, Vol. 3(2). Apr. 2004, pp. 154-161.
[6] Hans, Cousto, "The Cosmic Octave Turning Forks", Planetware, 2009.

[7] Gurjar, Ajay Anil and Siddharth A. Ladhake, “ Analysis and Dissection of Sanskrit Divine Sound 'OM' using signal processing to study the science behind 'OM' Chanting', $7^{\text {th }}$ Int. Conf. on Intelligent Systems, Modeling and Simulation, IEEE Computer Society, 2016.

[8] https://www.booksfact.com/mantra-sastra/mantrasfrequencies-heal-kill-transcend.html

[9] Sharma, Shriram Acharya, "The Integrated Science of Yajna" Shantikunj, Haridwar, 2011.

[10] Devi, Meenakshi; "Beej Mantras, https://kamakhyabhaktilalbaba.wordpress.com, Oct 24, 2013.

[11] Gabriel, Roger; "How to use sound to heal yourself". www.chopra.com

[12] "What are Brain Waves?", www.curlsonmeloncelli.com

[13] "Beam Frequencies", Scientific American, 22 Dec 1997.

[14] Cousto Hans, "The Cosmic Octave Turning Forks", Planetware, 2009.

[15] Turner, Ashley, "How meditation changes your brain frequency" www.mindbodygreen.com Feb5,2014.

[16] Jean Paul Banquet, EEG \& Clinical Neurophysiology, Vol.33, 1972, p. 454.

[17] Wallace, Robert Keith, Ph.D. Thesis, School of Medicine, University of California at Los Angeles, USA, 1970.

[18] Dhar, H.L., "Meditation Therapy in Cardiovascular and Metabolic Disorders Special Reference to Coronary Artery Disease and Diabetes", Bombay Hospital Journal, Vol. 51, No. 4, 2009, p.474.

[19] Selvamurthy, W. "Physiological Effects of Mantras on Mind and Body" Presented in Yoga Conference held at IIT, Delhi on 4th November, 1989. 